\title{
Cosmetic Ventilators (Co-V) for COVID-19
}

\author{
Anand S Malani
}

\begin{abstract}
The COVID-19 pandemic has infiltrated all over our lives in every aspect and led to complete lockdown in almost every country and affected millions of people. It has overwhelmed the healthcare systems even of the most developed nations and this could be our future as well if situation is not controlled. We might fall short of ICU beds, ventilators, and trained manpower. Having understood that, many companies or even individuals have started to produce new and innovative kind of ventilators which prima facie are not at par with the standard ICU ventilators. Such ventilators, if approved for use in COVID-19 acute respiratory distress syndrome (ARDS), may not be of much use and rather cause harm. This commentary shall deal with the basics of COVID-19 ARDS, basics of an ICU ventilator, innovative low-cost ventilators, and the stark differences between the two and why their use may not be appropriate in the condition of our concern.

Keywords: Acute respiratory distress syndrome, COVID-19, Indian Society of Critical Care Medicine, Pandemic, Ventilator, Ventilator-induced lung injury.

Indian Journal of Critical Care Medicine (2020): 10.5005/jp-journals-10071-23436
\end{abstract}

We are all aware of the present COVID-19 pandemic, also being the headline of every media platform available. Within a short period of time it has overwhelmed healthcare systems of Europe and the United States, being an unprecedented occurrence. Relative lack of ICU beds, ventilators, and healthcare manpower in other countries are forcing hospitals to ration ${ }^{1}$ patients for life and death. Fortunately, we Indians are lucky enough to flatten the curve until now, owing to some excellent and unequalled measures taken by our government and cooperation from its citizens. Let's hope this trend continues and corona fades away!

What if things go the European way? Well then our systems too will be overwhelmed in a matter of days and we will be forced to ration as well, scary! Isn't it? This article shall deal with 'innovative low-cost ventilators ${ }^{\prime 2,3}$ and why their use may NOT be appropriate. It also includes story of such innovator and problems associated with these ventilators. Let's begin.

According to an estimate by Indian Society of Critical Care Medicine (ISCCM), the whole of India has only 40,000 functioning ventilators, including both public and private sector hospitals. Considering that on an average $20 \%$ of total ICU beds are ventilated, then our number of critical care beds will be approximately 2 lakhs. That's meager considering our population of 130 crores, even in normal circumstances, leave aside sufficiency during a pandemic of this magnitude.

Many hospitals are being converted into COVID-19 hospitals and ICUs. Such hospitals will need a large number of ventilators; a few lakhs or even a million will not be an overestimate. It's impossible for us to arrange, manufacture, or import in those numbers!

Having understood that, unsurprisingly, many biomedical companies, start-ups, automotive industries, engineering institutions, and even many intellectuals from all faculties are coming out with 'innovative low-cost ventilators' ${ }^{\prime 2,3}$ and claiming mass production capabilities. Prima facie what a relief! These all are receiving heaps of praises from common man, the medical fraternity, and the media and government machinery too.

Well, nothing wrong in innovation, especially at such precarious times, nothing at all! But all of the innovation will be futile if the purpose is not being served. Especially if we are made to believe that the purpose is being served without being served, either
Department of Critical Care and Medicine, Spandan Critical Care Unit and Medical Nursing Home, Sangli, Maharashtra, India

Corresponding Author: Anand S Malani, Department of Critical Care and Medicine, Spandan Critical Care Unit and Medical Nursing Home, Sangli, Maharashtra, India, Phone: +91 9823084793, e-mail: dranandsm@gmail.com

How to cite this article: Malani AS. Cosmetic Ventilators (Co-V) for COVID-19. Indian J Crit Care Med 2020;24(7):506-508.

Source of support: Nil

Conflict of interest: None

knowingly or unknowingly! And that's cosmetic about it, 'Cosmetic Ventilators for COVID-19'.

Let us try to understand why? This involves understanding of at least basics of the disease and the ventilators. A severe COVID-19 infection progresses to viral pneumonia and finally acute respiratory distress syndrome (ARDS), ${ }^{4,5}$ where severe infection and the resultant inflammation of the lung tissue results in altered gas exchange function and altered microhemodynamics, resulting in severe hypoxic respiratory failure. In simple words, severe oxygen deficiency at the organ and tissue level, which will ultimately result in death.

If we go into more detail, COVID-19 presents with very much atypical form of ARDS named as L phenotype ${ }^{6}$ in some and the more typical form of ARDS named as $\mathrm{H}$ phenotype in others and $\mathrm{a}$ whole spectrum in-between the two.

This differentiation is very important as ventilator strategy will change accordingly. Apart from this, new theories about pathophysiology are coming up needing further studies. Without going in further details, I still believe that the resultant lung injury will still qualify as ARDS, and the ventilatory strategies will remain same.

Without going into details of mechanical ventilation and ventilators, let me put it straight that a ventilator helps in correcting hypoxia and other coexisting gas exchange and acid-base/ metabolic abnormalities. This is achieved by promoting gaseous

() The Author(s). 2020 Open Access This article is distributed under the terms of the Creative Commons Attribution 4.0 International License (https://creativecommons. org/licenses/by-nc/4.0/), which permits unrestricted use, distribution, and non-commercial reproduction in any medium, provided you give appropriate credit to the original author(s) and the source, provide a link to the Creative Commons license, and indicate if changes were made. The Creative Commons Public Domain Dedication waiver (http://creativecommons.org/publicdomain/zero/1.0/) applies to the data made available in this article, unless otherwise stated. 
exchange at the alveolar level by using positive pressure and complex principles of physics and a very complex interplay with the pathophysiology. Please remember that it is a form of organ support, till the organ recovers or refuses to recover (death). It does not affect the disease process as such.

Coming back to ARDS, it is a very complex disease, and asymmetrical one. Different areas of lungs get affected in different proportions and severity. Apart from that there are atypical forms of ARDS associated with COVID-19 as I mentioned earlier.

The diseased lung behaves as baby lungs, difficult to keep alveoli open, low compliance, highly prone for barotrauma, etc., and the non-diseased part of lungs behave as normal or adult lungs. There lies a whole spectrum in-between. When you ventilate, essentially you have to ventilate the baby lung and the normal lungs and everything else together!

That's the reason an ARDS needs an ICU ventilator, ${ }^{7,8}$ not a crude one or one developed just for the sake of it.

The ICU ventilators are the product of advanced research and patience with continuous improvisations and innovations, delivering a precision. The ICU ventilators are comprehensive capability units. I will like to cite a very beautiful article that appeared in Breathe, June 2017, “Trends in mechanical ventilation: Are we ventilating our patients in the best possible way?" ${ }^{77}$ detailing about the evolution of complex ventilators. This review addresses how the combination of physiology, medicine, and engineering principles contributed to the development and advancement of mechanical ventilation.

They have the capabilities to deliver and fulfill the complex requirements of ARDS ventilation, ${ }^{9}$ not just blow in and blowout. They are accurate to the least counts of volume, pressure, time, flow, and numerous other parameters required to be set on it.

They are capable of running for hours, weeks, months, and sometimes even years in one go without any interruption or failure on any aspect. They are approved by international technical and medical institutions, e.g., CE certification, US FDA approval, and many others that differ countrywise, and can never be brought into the market without the requisite approvals.

Certainly, the costs of ICU ventilators are high. A single ventilator from a reputed or specialist company will set you back by Rs. 10-25 lakhs.

The expertise to use these machines is equally important. ${ }^{10}$ It needs highly trained medics and paramedics to use them in a way they are intended to. And they are in short too! The machines will be of no use if the expertise is unavailable. Let us compare ventilator controls to the complex cockpit of an airplane and administrator expert to the pilot. With no proper experts handling the ventilator, it would be like pilot trained in flying a small personal plane made to fly the A-380 jetliner with no training or experience. I would certainly not be on board of such a plane!

Let us look at the mortality rates in ventilated COVID-19 patients. Certainly, it is above $60 \%,{ }^{11}$ with some variations, even in best hospitals of the world using best ICU ventilators. There is a subset of patients, which are not manageable by ventilators, and those need to undergo extracorporeal membrane oxygenation (ECMO), in other words artificial lungs.

Having understood some basics of the disease and the ventilators, let me come back to the topic of concern. We all are aware that this pandemic has triggered an innovation race among biomedical and nonbiomedical companies, e.g., automobile industries, start-ups, technical institutions, and even individuals to come up with innovative ventilators, the low-cost ones and the mass producible ones, more so in India than the West.

Necessity is the mother of inventions. And this pandemic has given many a golden chance to innovate and help the mankind. For some this is also a chance to get noticed as well as earn some bucks! It is highly appreciable that some companies like Tesla are manufacturing ventilators from its automobile components and have come quiet closer to the ICU ventilators and have promised to supply them free of costs! But they would certainly need to go through the necessary approvals before being put to use.

But most of the innovations do not fulfill the necessary requirements and are miles away from being put to use in ICU or in ARDS. It will certainly be a reason for apprehension when these innovators, either a person or a team, learned and trained in some other faculty, tries to develop something distant and unrelated to their expertise. Let's consider an example of an automotive manufacturer who is trying to manufacture an airplane from scratch, within a short time, and fly within days if not by night! What is the chance that this plane will fly successfully and land safely? How many of us will like to be on board? None! It is exactly the same when it comes to ventilators.

On a serious note, many of these ventilators will not be useful in real-life scenarios, especially COVID-19, and can even be dangerous and increase mortality. In fact even ICU ventilators may increase the mortality if the strategy applied is inappropriate for that patient.

Ventilator-induced lung injury (VILI) ${ }^{12}$ is common in COVID-19. Especially the $L$ phenotype, which is atypical ARDS, if the same strategy is used as for typical ARDS. Even the stalwarts in ARDS and ventilation are yet to reach a consensus on the best strategy.

The basis of my concern was generated when I witnessed one such prototype of innovation, and its extrapolation to others, which I think are more or less on similar lines. I also admit that I had helped an innovator at the outset who was eager to manufacture a ventilator, by providing basic information of the same and later discouraged, as I felt he was overambitious. Just to avoid complete disappointment, I suggested him to go for mechanized AMBU bag, which may be of use in resuscitation or transportation only.

To my surprise, in less than 3 days, I was called up for a demonstration of his newly developed, so-called ventilator. As expected, it was a crude one:

- Without flow sensor

- Without trigger

- Tidal volume in multiples of $x$ and PEEP in multiples of $y$

- No display of patient or machine-delivered parameters

- No alarms and graphics a distance away!

And the graphics part was considered cosmetic and nonessential by the innovator! The improvised version did have some improvements, an added trigger, and pressure alarms; somehow the PEEP was completely missing, and had an interesting mode, perhaps a new one, "the PRUVC mode, pressure regulated unassured volume control."

Here the cycle used to cut-off after a certain pressure was achieved without any assured volume. For example, the volume delivered will be zero if the tube is partially occluded and raises the airway pressure beyond the set value. No concept of minute ventilation.

Later, I lost interest and track of that except for the fact that is was being claimed to match international brands and was on news and social media! Let's be honest. Considering everything, how 
many of us will believe their claim of being equating to international standards?

Criticism apart, such "open-source category"13 kind of ventilators, which in fact qualify as 'limited-capability units' with some improvisations, may be considered for use in conditions requiring ventilator with non-diseased lungs, in a resource-limited settings. And that's it! Certainly not in a condition like COVID-19, even though a pandemic and a disaster situation.

Many other models developed by different enthusiasts were seen on social media, e-news, etc. The prominent ones being the low-cost mechanized AMBU, the ventilator running on only gas pressure without power and even seen as a "multi-patient ventilator," beyond my imagination! Plus these were receiving lot of accolades and likes from public, media, and medical fraternity too.

I am waiting for some real-life Rancho (a science-crazy Bollywood film character known for innovations) to develop a ventilator from vacuum device (after the successful use of Ventouse for a home delivery in adverse conditions) and a ventilator with the APRV mode from the blower of the same device in a similarly adverse present COVID-19 pandemic condition!

Jokes apart, on a serious note, a lot of research, trial errors, and improvisations will be needed before such equipment are approved and put in for clinical use, and which certainly will have a long gestation period. I am sure that many of these won't get approvals from the concerned bodies in the West for clinical use, unless standards are met.

I fear that these may be approved in our country or for that matter any other as well, considering an unexpected, unprecedented crisis staring at us! There will be a strong argument that 'something is better than nothing.' In fact, 'Nothing will be Better than Something' if that something doesn't do any good or does harm. I always remember our very first lessons of "primum non nocere", a latin phrase meaning "first, do no harm."

This pandemic has created panic all over and everyone is in search of 'rapid solutions'. That's the reason, I think, which will facilitate rapid approvals of the 'innovative armamentarium'. A scientific approach will always take a back seat than 'a hope and a layman's view' during such precarious times. If at all these ventilators are approved and used, it will be for cosmetic purpose only from my standpoint. All will be happy, the state, the patient's families, the society, and a large of medical fraternity as well - that a ventilator was available and was put to use.

Just before I conclude, I will like to request the ISCCM, the apex organization of critical care in India, to include few lines about such innovative ventilators in their position statement and take active part in evaluation and approvals of the same.

"A critic must provide alternative solutions and the answers"; honestly, I don't have any, I admit. The previously unapproved modalities of ventilation in COVID-19, CPAP/HFNO, ${ }^{9}$ etc., are now being approved in certain subsets of patients and in a controlled environment. May be there is scope for innovation and mass production in these, as these are relatively simpler than the complex
ICU Ventilator. Yes, the innovations must continue and should be encouraged. Only condition being that these should be based on scientific research and development, and not on emotions or wishful thinking.

Even if all the innovative armamentarium improvises upon and is at our disposal, the availability of credible and qualified specialists in bulk will still remain a very big question!

\section{References}

1. White $D B$, Lo B. A framework for rationing ventilators and critical care beds during the COVID-19 pandemic. JAMA 2020. DOI: 10.1001/jama.2020.5046. https://jamanetwork.com/journals/jama/ fullarticle/2763953.

2. Volunteer engineers and physicians created open-source, cheap ventilators that could be used in ERs of the future. Cory Stieg, Published Wed, Apr 22 20201:40 PM EDT. https://www.cnbc. com/2020/04/22/mit-volunteers-created-open-source-low-costventilator-for-covid-19.html.

3. Coronavirus: India's race to build a low-cost ventilator to save Covid-19 patients. Soutik Biswas, India correspondent. https://www.bbc.com/ news/world-asia-india-52106565.

4. Acute Respiratory Distress Syndrome (ARDS) Treatment \& Management. Eloise M Harman, MD Staff Physician and MICU Director, Pulmonary Division, Gainesville Veterans Affairs Medical Center. https://emedicine.medscape.com/article/165139-treatment\#d10.

5. Papazian L, Aubron C, Brochard L, Chiche J-D, Combes A, Dreyfuss $D$, et al. Formal guidelines: management of acute respiratory distress syndrome. Ann Intensive Care 2019;9(1):69. DOI: https:// annalsofintensivecare.springeropen.com/articles/10.1186/s13613019-0540-9.

6. Gattinoni L, Chiumello D, Caironi P, Busana M, Romitti F, Brazzi L, et al. COVID-19 pneumonia: different respiratory treatments for different phenotypes? Intensive Care Med 2020. DOI: https://link.springer. com/article/10.1007/s00134-020-06033-2.

7. Dellaca' RL, Veneroni C, Farre R. Trends in mechanical ventilation: are we ventilating our patients in the best possible way? Breathe (Sheff) 2017;13(2):84-98. DOI: 10.1183/20734735.007817. https://www.ncbi. nlm.nih.gov/pmc/articles/PMC5467868/.

8. Intensive care ventilators,. Health Devices 1998;27(9-10):308-362. https://pubmed.ncbi.nlm.nih.gov/9809256/.

9. Mehta Y, Chaudhry D, Abraham OC, Chacko J, Divatia J, Jagiasi B, et al. Critical care for COVID-19 affected patients: position statement of the indian society of critical care medicine. 2020. https://isccm.org/ pdf/ijccm23395.pdf.

10. Divatia JV, Baronia AK, Bhagwati A, Chawla R, lyer S, Jani CK, Critical Care Delivery in Intensive Care Units in India: Defining the Functions, Roles and Responsibilities of a Consultant intensivist. https://isccm. org/pdf/ISCCM\%20Intensivist\%20guidelines.pdf.

11. Higher Mortality Rate in Ventilated COVID-19 Patients in Large Sample Diana Swift. April 13, 2020. https://www.medscape.com/ viewarticle/928605.

12. Marini JJ, Gattinoni L. Management of COVID-19 respiratory distress. JAMA 2020. DOI: 10.1001/jama.2020.6825. https://jamanetwork.com/ journals/jama/fullarticle/2765302.

13. Open-source ventilator. https://en.wikipedia.org/wiki/Open-source_ ventilator. 